\title{
Inclusive Design as a Market Differentiator: An Industry and Academic Perspective on Diversity-Driven Initiatives in Built Environment Design Across North America, Europe, the UK, and Australia
}

\author{
Jenna MIKUS ${ }^{\mathrm{a}}$ and Janice RIEGER ${ }^{\mathrm{a}}$ \\ ${ }^{a}$ Queensland University of Technology, Faculty of Engineering, \\ School of Architecture and Built Environment
}

\begin{abstract}
Industry and academic perspectives have become more focused on designing for Diversity and Inclusion (D\&I) over the past few years, both in general and particularly within the built environment. This renewed interest appears to have stemmed from a basis of respect-based 'due diligence' in 2018 to one of necessity in 2020, when the COVID-19 pandemic brought areas of difference into focus and exacerbated them, making it harder for people to live their everyday lives. In this paper, the authors seek to bridge the divide between academia and industry on the subject of Inclusive Design (ID) through their use of a combination of an academic and grey literature review as well as empirical research conducted with scholars and practitioners. These multiple methods focus less on the academic perspectives and more on how the industry has responded to the research and market demand. It clarifies nuanced differences among ID-related terms, provides best practice examples for wellness in the built environment, and identifies governing body guidelines (i.e., principles, protocols, policies) that have been enacted for ethical and business differentiating purposes.
\end{abstract}

Keywords: Universal Design; Design for All; Business Strategy; Equity; Inclusion; Architecture

\section{Introduction}

This paper explores the evolution of Inclusive Design - its related terminology, projects, and governing guidelines and policies - in the built environment as an equity-based design approach that is "not just about good intentions-it is also about good business" [1]. Accessible Design, Universal Design, Design for All, and Inclusive Design are often considered to be interchangeable terms in industry and academia; however, they have different origins and thereby different meanings, nuances, and geographic areas of application $^{1}$.

${ }^{1}$ Other recognised terms exist, such as Human-centred Design, Assistive Design, and more. However, for the purposes of this paper, the focus is on Inclusive Design and its related Accessible Design, Universal Design, and Design for All terms. 
The more commonly used and accepted Inclusive Design term is less about designing for empathy [2], charity [3-5], or diversity [6] and more about having a respectful, human-centred approach to "designing places that all people can use" by focusing on comprehensive health and well-being [7]. As a consequence, for the purposes of this paper, Inclusive Design is considered the optimal term and will be used to refer to this general grouping of terms, though all terms will be explored individually.

Inclusive Design is a good procedural principle in theory and more recently in practice. Like many best practices, it is now being recognised and embraced by companies, design firms, and governing bodies for its ability to meet requirements as well as its appeal as 'the right thing to do.' Design done equitably within the built environment has the potential to 'raise the bar' across communities to address physical, mental, and social health and well-being disparities highlighted as a result of the COVID-19 pandemic.

Consideration of the ethical and business purposes behind Inclusive Design in the Built Environment facilitates knowledge sharing across what has been perceived as an academia/industry chasm and therefore promotes research scholarship into actionable form by built environment practitioners. While this paper pays particular attention to work done across three continents-North America (e.g., the United States (US), Canada), Europe (including the United Kingdom (UK)), and Australia - the underlying theme is the importance of and need for diversity and inclusion via Inclusive Design practices across research and practice worldwide.

\subsection{The Need for Inclusive Design}

According to the American Society of Landscape Architects, as of 2019, one billion people in the world ( $15 \%$ of the world's population) experience some form of disability [8]. This data is reinforced by the World Health Organization in their 2020 report on Disability and Health worldwide [9]. However, considering the growing recognition and occurrence of neurodiversity found in North America in particular, this previously identified $15 \%$ may be an underapproximation [10]. While $1 \%$ of the world's population requires a wheelchair due to physical disabilities, nearly $20 \%$ are considered neurodiverse, those who experience a variety of neurological conditions (e.g., depression, anxiety, dyslexia, Obsessive-Compulsive Disorder (OCD)) [11].

As individual well-being can be tied to that of communities, cities, and even the globe via social sustainability principles [12], it would behoove all if design were done proactively and intentionally up front to support comprehensive health and well-being from a physical, social, and mental point of view, rather than primarily physical, as has been done to date [13]. Inclusive Design offers such an approach.

\subsection{The Value of Inclusive Design}

Academic research has discussed the value in Inclusive Design since the mid 2010s [1418]. However, over the past two years, companies, design firms, and governing bodies have begun to recognise the deeper value in employing designing for Diversity and Inclusion (D\&I), identifying it as an ethical responsibility as well as a decision that positively impacts the bottom line. 
When COVID-19 hit in early 2020, the pervasive divides across ability, gender, race, and socio-economic status were exacerbated and could no longer be ignored. Inclusive Design practices needed to become something that was less a "specialization" as Rieger and Iantkow (2021) characterise it and more as a paradigm-shifting norm [19].

This paper focuses less on the ethics behind doing Inclusive Design and more on the newly recognised market value of doing so. McKinsey \& Company has presented three reports on D\&I since 2015 [20]. The most recent report published in May 2020 continues to tout the value of D\&I for business in their report entitled "Diversity Wins: How Inclusion Matters" but turns the D\&I on its head, emphasising the idea of Inclusion to address Diversity in their use of I\&D (Inclusion and Diversity), rather than the more commonly used D\&I acronym. It argues that "diversity and inclusion matter more than ever" when considering the COVID-19 crisis and calls it a "powerful enabler of business performance" [21].

The application of D\&I (or I\&D) principles in the built environment has parallel value. Companies requiring design, design firms, and design governing bodies all are businesses in their own right. They have employees and clients. By intentionally implementing Inclusive Design into design and operational efforts, they are likely to validate feelings of company care, heighten brand and market valuation, increase client statistics (i.e., quality and quantity), and improve social [19,22] and environmental sustainability, given that it requires less adaptation and is therefore more sustainablethus good for business and the planet [23]. The difference between design companies and general business companies lies in their potential for greater impact.

\subsection{The Value of Inclusive Design for Design-related Business}

The Americans with Disabilities Act and the World Health Organization both recognise that many physical, social, and mental health challenges whether disability [24] or agerelated [25,26] can be addressed through environmental design [27]. Therefore, it can be argued that design companies differ in that they do not only benefit from a business perspective. They also have the ability to support people in their homes, workplaces, public spaces, and more, through human-centred design.

As Goldhagen argues, "Designers absolutely should have freedom to innovate, to explore, and to problem-solve. But they need to do so with the framework of humancentered built environmental design" [28]. Designers have the capability and responsibility to curate environments that support human health. Therefore, it is important that the Inclusive Design approach be discussed in an understandable and equitable way, beginning with its history, to apply as standard protocol in the future.

\section{Approach/Method}

The primary research methods for this paper include an academic and grey (i.e., industryconducted) literature review and semi-structured interviews conducted with five Inclusive Design-related experts across North America, Europe and the UK, and Australia in academia and industry. Using these methods, the authors shed light on the 
nuance across Inclusive Design practice by focusing on three areas across the three target continents: exploring taxonomy lineage, evolution, and current status; highlighting noteworthy Inclusive Design-supportive projects across typology; and reviewing preexisting and new certification bodies that promote Inclusive Design in indoor and outdoor environments through updated guidelines, principles, protocols, and policies.

\section{A History of Inclusive Design}

Over the past few decades, the design community has explored methods of humancentred Inclusive Design. Based on historical origin and regional application, these terms vary among Accessible Design [29,30], Universal Design [16,31-33], Inclusive Design [1,3-5,7,14,15,17], and Design for All [34-38]. While all four terms are related, the latter three are most similar in providing an equitable approach to design rather than a compliance-focused one.

\subsection{Inclusive Design-related Terminology-Origin, Nuance, Status}

In this section, all four terms are discussed, including their originating date, geographic application, origin background, context and considerations, academic definition, and industry application, as depicted in Tables 1-4.

Table 1. Accessible Design Summary

\begin{tabular}{ll}
\hline & \multicolumn{1}{c}{ Accessible Design } \\
\hline Date & North America (e.g., the US) \\
\hline Geographic Region & $\begin{array}{l}\text { Accessible Design developed out of the Fair Housing Amendments Act } \\
\text { (1988); the Center for Accessible Housing (1989); and the Americans } \\
\text { with Disabilities Act (ADA) (1990). }\end{array}$ \\
\hline Origin & $\begin{array}{l}\text { The ADA's instantiation was a landmark event in 1990 [30]. It marked a } \\
\text { global first in the creation of a national law to explore and protect access } \\
\text { for all in the built environment. Thus, it became a model for guidelines in } \\
\text { other (especially English speaking) countries and for the United Nations } \\
\text { Convention on the Rights of Persons with Disabilities [39]. The ADA was } \\
\text { the first to use Accessible Design. }\end{array}$ \\
\hline Definition (Academic) & $\begin{array}{l}\text { According to the University of Washington, "Accessible design is a } \\
\text { design process in which the needs of people with disabilities are } \\
\text { specifically considered" [40] }\end{array}$ \\
\hline Application (Industry) & $\begin{array}{l}\text { Accessible Design is often perceived as a means of design compliance for } \\
\text { addressing physical disabilities. It rarely results in meaningful mental or } \\
\text { social health-focused design or in aesthetically pleasing designs. } \\
\text { Therefore, this is a less favourable and less used term, though it is } \\
\text { considered the foundation of Universal Design [41]. }\end{array}$ \\
\hline
\end{tabular}


Table 2. Universal Design Summary

\begin{tabular}{ll}
\hline Universal Design \\
\hline Date & \multicolumn{1}{c}{ U97 (though foundational work began in the 1970s) } \\
\hline Geographic Region & $\begin{array}{l}\text { North America (e.g., the US) and Australia (with some use in Europe } \\
\text { (e.g., Norway)) }\end{array}$ \\
\hline Origin & Universal Design was the brainchild of Ron Mace of the Center for \\
& Universal Design (CUD) in North Carolina State University (NCSU) [41]. \\
\hline Context/Considerations & $\begin{array}{l}\text { The } 7 \text { Principles of Universal Design were developed in 1997, by a } \\
\text { multidisciplinary group of built environment researchers and practitioners } \\
\text { led by Mace of NCSU. This work was further developed in 2012 when } \\
\text { the University of Buffalo's Center for Inclusive Design and } \\
\text { Environmental Access (IDeA Center) created } 8 \text { Goals of Universal } \\
\text { Design that focused more on outcomes, rather than goals. }\end{array}$ \\
\hline Decording to IDeA, "Universal design means planning to build physical, \\
learning and work environments so that they are usable by a wide range \\
of people, regardless of age, size or disability status. While universal \\
design promotes access for individuals with disabilities, it also benefits \\
others" [42]. Both the CUD at NCSU and the Norwegian Ministry of \\
Children, Equality and Social Inclusion define Universal Design as "the \\
design of products and environments to be usable by all people, to the \\
greatest extent possible, without the need for adaptation or specialized \\
design" [22,40].
\end{tabular}

Table 3. Design for All Summary

\begin{tabular}{|c|c|}
\hline & Design for All \\
\hline Date & 1993 \\
\hline Geographic Region & Europe (with some use in Australia) \\
\hline Origin & $\begin{array}{l}\text { The term Design for All is most attributed to having originated with the } \\
\text { European Institute for Design and Disability (EIDD), which defined } \\
\text { Design for All upon EIDD's } 1993 \text { founding in Dublin [44]. }\end{array}$ \\
\hline Context/Considerations & $\begin{array}{l}\text { While often used in conjunction with Universal Design, the term Design } \\
\text { for All offers a more understandable and actionable terminology that } \\
\text { originated from the } 1960 \text { s Scandinavian welfare political concept of 'a } \\
\text { society for all' [45]. }\end{array}$ \\
\hline Definition (Academic) & $\begin{array}{l}\text { According to the } 2004 \text { EIDD Stockholm Declaration "Design for All is } \\
\text { design for human diversity, social inclusion and equality" [35]. It focuses } \\
\text { on human diversity, rather than disability compliance. }\end{array}$ \\
\hline Application (Industry) & $\begin{array}{l}\text { Design for All is most used in Europe by EIDD member nations, } \\
\text { especially those in Scandinavia (e.g., Norway), with some referencing in } \\
\text { Australia [37,46]. It is likely to continue to gain traction in academic and } \\
\text { industry use due to its relatability. As Paul Hogan, EIDD-Design for All } \\
\text { Europe President Emeritus, put it "Good design enables, bad design } \\
\text { disables" [44]. That simple yet effective quote captures the essence of } \\
\text { Design for All. }\end{array}$ \\
\hline
\end{tabular}


Table 4. Inclusive Design Summary

\begin{tabular}{|c|c|}
\hline \multicolumn{2}{|r|}{ Inclusive Design } \\
\hline Date & 1994 \\
\hline Geographic Region & North America (e.g., Canada); the UK \\
\hline Origin & Inclusive Design was first used at a conference in Canada in 1994. [47] \\
\hline Context/Considerations & $\begin{array}{l}\text { While Inclusive Design is similar to Europe's Design for All and the US' } \\
\text { Universal Design terms, it has one important difference. It has evolved } \\
\text { into a more universally accepted taxonomy and accounts for the intent of } \\
\text { the approach, the resulting design, as well as the process pursued. }\end{array}$ \\
\hline Definition (Academic) & $\begin{array}{l}\text { Per Clarkson and Coleman (2013) "Inclusive Design (also known [in } \\
\text { Europe] as Design for All and as Universal Design in the US) is in essence } \\
\text { the inverse of earlier approaches to designing for disabled and elderly } \\
\text { people as a sub-set of the population, and an integral part of a more recent } \\
\text { international trend towards the integration of older and disabled people in } \\
\text { the mainstream of society" [48]. }\end{array}$ \\
\hline Application (Industry) & $\begin{array}{l}\text { Inclusive Design is described by the Commission for Architecture and the } \\
\text { Built Environment (CABE) as "a process of designing, building, } \\
\text { managing and populating places and spaces that ensures that they work } \\
\text { for as many people as possible, not just some groups. It encompasses } \\
\text { where people live and the public buildings they use, such as health } \\
\text { centres, education facilities, and libraries; and how they get around- } \\
\text { neighbourhoods, streets, parks, and green spaces and transport" [49]. } \\
\text { Similar to Universal Design, "Inclusive Design aims to design } \\
\text { mainstream products, services and environments that are accessible and } \\
\text { attractive to the largest possible number of people" [1]. In the paper, } \\
\text { which introduces Inclusive Design, Coleman suggests that the } \\
\text { differentiation relates to HOW design is done. He posits that "fresh } \\
\text { approaches... are needed to bridge the present gulf between mainstream } \\
\text { design and design for the elderly, especially with regard to the scale of } \\
\text { demographic change. The concept of Inclusive Design coupled with } \\
\text { storytelling and scenario building techniques can turn what is often } \\
\text { considered as a branch of design for disability into an exciting gateway to } \\
\text { product innovation and a more user-friendly future for all" [47]. With that, } \\
\text { Inclusive Design offered more than just similar perspectives to those of } \\
\text { Universal Design and Design for All. It questioned how meaningful } \\
\text { design could be done better-making it at once both challenging and } \\
\text { intriguing. }\end{array}$ \\
\hline
\end{tabular}

\subsection{Reflection (Similarities and Differences)}

While Accessible Design played a key role in founding Inclusive Design-related terms and practices, it is considered more limited in its viewpoint and therefore a less favoured term. The latter three terms described above are more similar. They all value the perspective of the user and seek to empower users.

Some practitioners and academics argue that Universal Design, Design for All, and Inclusive Design are similar versions of the same idea applied in different geographies (i.e., the US, Europe, and the UK, respectively) [48]. However, the authors believe that Inclusive Design's more strategic approach to design makes it a market differentiator. It ingrains the approach in a 'design for good' type mindset and challenges designers to try 
new ways of meaningfully engaging users for design, whether through storytelling and scenario building as Coleman suggests [47] or through alternative methods.

Inclusive Design is similar to Europe's Design for All and the US' Universal Design terms, but it has one important difference in that it focuses on the WHY, the WHAT, and the HOW to make this approach come to fruition for organisations that truly wish to make a difference. In essence, Inclusive Design in its definition becomes its own best practice and protocol. It is therefore the term that these authors favour and therefore provide projects and policy examples of in the following sections to emphasise better Inclusive Design for better business.

\section{Inclusive Design Projects to Advocate for Better Design for Better Business}

This section highlights noteworthy projects that exhibit Inclusive Design in the built environment, and in business. While some projects are referred to as representing Universal Design, Design for All, or Inclusive Design, they are all considered good practice examples of Inclusive Design, given their robust intentional design and comprehensive health and wellness-supporting result. The projects below were chosen based on their diverse geography, diverse design typologies, and case study research the authors conducted. The projects are organised by continent: North America (e.g., the US, Canada); Europe (e.g., Sweden, Greece) and the UK; and Australia.

\subsection{North American Example Inclusive Design Projects}

The chosen examples in North America include a home and a university in the US, and a museum in Canada.

- $\quad$ Laurent House in Rockford, Illinois, US (1952): This single level home was built for a paraplegic man and his wife. As Frank Lloyd Wright's only building designed for a disability, it is noteworthy in its approach to light and wind, given its hemicycle footprint, its connection to nature (e.g., views, water access), and its accessibility in the interior (e.g., larger bathrooms) and exterior (e.g., navigable carport) [50]. It is often referred to as Wright's "Little Gem".

- DeafSpace at Gallaudet University in Washington, DC, US (2005): DeafSpace represents the approach taken when doing built environment design at Gallaudet University, an internationally recognized university designed for deaf or hearing disabled people "to fit their unique ways-ofbeing" [51]. This design approach employed at Gallaudet has resulted in DeafSpace Concepts or guidelines that include 'sensory reach' (e.g., open sightlines, spatial awareness), 'space and proximity' (e.g., distancing for "signing space"), 'mobility and proximity' (e.g., communication while moving), 'light and color' (e.g., visual communication without distraction and eye strain), and 'acoustics' (e.g., reverberation and background noise avoidance). This intersensory approach to spatial design is an excellent example of Inclusive Design that empowers individuals and promotes health. 
- Canadian Museum for Human Rights (CMHR) in Winnipeg, Manitoba, Canada (2014): This museum included Inclusive Design in early conceptual design phases when it hosted public design sessions with the Council of Canadians with Disabilities (CCD) and other relevant groups (e.g., activists, researchers, practitioners) [52-54]. This led to a museum that seamlessly includes tactile wall and floor elements for wayfinding, mobile and digital media with open and closed captioning, physical navigating techniques for simplified mobility, intellectual disabilityfriendly integrated signage, and specially trained support staff. By incorporating Universal Access Points (UAP) that blend into the design, easier navigating is possible and visually appealing. Together, these demonstrate the intentionality of Inclusive Design in the museum design and emphasise it as "a landmark built to celebrate human rights" [55].

\subsection{European and British Example Inclusive Design Projects}

The examples chosen from Europe and the UK include older adult housing in Sweden, a tourist-friendly historical site in Greece, and a museum in the UK.

- SilviaBo Project's BoKlok Housing for Older Adults in areas of Sweden (in progress): Given the rising number globally of the older adult population, there is a high demand for housing that meets their comprehensive health needs while also being affordable. A recent partnership among Queen Silvia of Sweden, IKEA, and Skanska resulted in a project called SilviaBo to create affordable yet beautiful housing that includes side walkways and entrances, integrated technology for door and lighting control, and clear wayfinding and signage to assist dementia occupants [56]. Social interaction is a key emphasis [57], and sustainability principles have been integrated throughout (e.g., 1\% materials going to landfill) [58].

- The Parthenon Template Entrance at the Acropolis in Athens, Greece (2020): For years, access to the Acropolis challenged people with physical disabilities. However, late last year, the site was redone to include a wheelchair-friendly lift and smoother stone paths for easier navigating. These design updates "make the Acropolis accessible to everyone ... without the difficulties associated with the classic route up to the Hill of Acropolis" [59].

- The Wellcome Collection Museum in London, UK (2019): Museums are often the scene of what is known as "routine discrimination" when considering people with disabilities [60]. In addition to addressing common accessibility needs [61], The Wellcome Collection's new Being Human gallery [62] differs by incorporating tactile models, a variety of audio and visual guides, more advanced audio description, clearly marked exits for people with anxiety, and more [63]. By consulting Inclusive Design in museum experts and including iterative feedback loops with "deaf, disabled, and neurodiverse people during the gallery's development and after it opened", the gallery has been touted as "a standard-bearer in 
inclusive exhibition design" [60] and dubbed "The World's Most Accessible Museum" by the New York Times [63].

\subsection{Australian Example Inclusive Design Projects}

The examples chosen from Australia include a public walking space for users who are vision impaired or blind, and an office space.

- The Braille Trail in Brisbane, Queensland, Australia (1989): Originally established on the Queen Street Mall in 1989, Brisbane's Braille Trail is a pathway of paved dots and dash patterns that can be followed by a person who is blind or has low vision, using a cane [64,65]. Tiles with ridges indicate the direction of travel along the trail, and tiles with paved dots warn of changes in direction or upcoming hazards. At about 1.6 kilometres in length, the Brisbane Braille Trail network is the longest continuous braille trail in Australia [66].

- $\quad$ Mirvac's Headquarters in Sydney, New South Wales, Australia (2016): As a WELL Certified Gold space and award winner, Mirvac's headquarters in Sydney is considered the 'world-first' timber closed cavity façade that incorporates a shading system [67]. Together, these balance visual interest from the timber's natural fractal patterns, access to daylight, and energy savings. With the incorporation of plants for biophilia, open spaces to encourage easy access and interconnectedness, and technology (e.g., sensors) to anticipate and accommodate occupant needs, an inclusive approach is taken to designing for health.

\section{Inclusive Design Policy to Mandate Better Design for Better Business}

This section explores policies that have been put in place to document best practices and establish them as an achievable bar against which to measure progress. The two examples explored are both based in the US and have international applications - one relates to the internal built environment and the other, to the external.

Given the US' early history with Accessible Design, it had an early start when considering "barrier-free design". While this can be seen as an advantage, it has also resulted in a hesitancy and inability to achieve more. For example, the existence of the ADA in the US led to many designers becoming complacent, satisfied when their designs met the minimal threshold standards instead of seeking to do more. For some time, this prohibited true comprehensive design. In an interview, an interior designer shared "The designers were constantly quoting ADA, and I was constantly criticizing them...and so sometimes, I have to say, okay, here you've got to walk in people's shoes. I will give you a real simple example: I was working on a community college and trying to explain to the architects what American Sign Language (ASL) interpreting was like. If you had an ASL interpreter in a classroom, what does that mean? And they were just not getting it. So I set up a meeting where I brought a very well respected member of the deaf community with me, who brought an ASL interpreter and we spent four hours in the architect's office reviewing drawings and at the end of it they got it" [54]. 
Fortunately, recent efforts by the American Society of Landscape Architects and the International WELL Building Institute provide hope for a more proactive approach for design and the policy that governs it.

\subsection{American Society of Landscape Architects Guidelines for Exterior Space Design}

Established in New York in 1899, the American Society of Landscape Architects (ASLA) was founded on a vision that promoted "healthy, beautiful, and resilient places for all" [68]. For years, ASLA protocols aligned with ADA requirements. However, given the number of underserved individuals (e.g., age, gender, race, disability, neurodiversity) [33] and the need for design equity in the public domain [69], ASLA recently recognised that simply meeting ADA requirements was no longer enough.

In September 2019, ASLA released Universal Design Guidelines for 5 topicsNeighborhoods, Streets, Parks and Plazas, Playgrounds, and Gardens to raise awareness of the need for more inclusive exterior spaces and provide guidelines on how to do that [8]. The new guidelines consider a variety of physical, mental, and social disabilities and explore landscape as a means to welcome and support those unique needs. Ian Dillon and Jared Green, the authors of the guide, go beyond the best practices discussed to offer simple examples that encourage adoption.

As the guidelines state "If we want everyone to participate in public life, we must design and build an inclusive public realm that is accessible to all. Public life can't just be available to the abled, young, or healthy" [8]. Indeed, as the Curbed article comments "It sounds like good design $101 \ldots$ It turns out that designing a space that's accessible to people of all abilities ultimately leads to better, more thoughtful spaces for everyone" [69].

\subsection{The WELL Building Standard for Interior Space Design}

The WELL Building Standard ${ }^{\mathrm{TM}}$ (WELL ${ }^{\mathrm{TM}}$ ) was launched by its parent company Delos Living LLC in New York in 2013. It is administered by the International WELL Building Institute (IWBI) "whose mission is to improve human health and wellbeing through the built environment" [70] and is certified by Green Building Certification Incorporated (GBCI). Because buildings play a significant role in the health and well-being of occupants, it is important they are designed with intention, in a way that is built on research and practice.

The first version of the WELL Building Standard (v1) provided guidance on how buildings could be designed for health, using science-based research to inform 100 features across 7 concepts: Air, Water, Nourishment, Light, Fitness, Comfort, and Mind [71]. Now in its second version, WELL v2 has updated the certification to include 108 features across 10 concepts: Air, Water, Nourishment, Light, Movement, Thermal Comfort, Sound, Materials, Mind, and Community [72].

The difference between the first and second versions, other than a few additional features and concepts, is its foundational focus on inclusivity. As Rachel Hodgdon, CEO of the IWBI, states "Aspects of universal design and inclusive design are peppered in 
throughout the entire standard" [73]. One such change involved transitioning WELL v1's Fitness into WELL v2's Movement concept to emphasise general mobility over physical fitness. Another involved reevaluating WELL v1's Feature 72: Accessible Design into v2's Feature C13: Accessibility and Universal Design to ensure physical access as well as a design for all approaches.

WELL continues to evolve with the COVID-19 pandemic. The WELL v2 standard now incorporates robust validation techniques to ensure buildings continue to meet the criteria and do not stray from previous performance. WELL has also formed a Task Force of 500 global experts to advise on COVID-19 and other respiratory infections. "Task Force members span dozens of countries and hail from a variety of sectors and industries, including public health, government, academia and businesses worldwide, as well as global architecture, design, building science and real estate communities" [74].

\subsection{The WELL Health-Safety Rating for Interior Space Maintenance}

WELL also launched a new WELL Health-Safety Rating in late January 2021 that ensures occupant health, well-being, and safety are foremost when considering facility operations and management. By providing 22 strategies relating to "best practice operational policies, maintenance protocols and emergency plans", WELL provides building owners and operators with the guidelines and tools they need to ensure their buildings are safe for occupants. In turn, occupants feel safer to enter those buildings and occupy those spaces.

While it is early days to assess the efficacy of the Rating, it can be considered a progressive step to provide policy and evidence-based actionable guidance on building operations, maintenance, and management, especially during a crisis such as COVID19. Regardless, the WELL standard and the brand itself is a paradigm of Inclusive Design to date, believing that "spaces can be great equalizers" [31], and designing for that in the research they enact into guidelines, the standards and services they provide, and the advocacy they do for health and wellness for all.

\section{COVID-19's Exacerbated Demand for Inclusive Design}

While having example projects and policies can help guide the design of communities, sometimes the unexpected occurs.

The year 2020 brought circumstances that heightened levels of anxiety and widened the divide among populations that differ (based on disability, race, gender, socio-economic status). However, design has the ability to overcome health, situation, and wealth disparity through design equity. Design focusing on diversity, inclusion, and more recently belonging [75] provides hope for the future and has the potential to ameliorate the inequities of today and the future.

\subsection{Designing for the Extraordinary (People, Environments, Circumstances)}

One researcher who argued for designing for differences was Alan Newell. He argued for Designing for the Extraordinary [76] back in 1993. While his work was situated with 
the field of Human Computer Interaction (HCI), the approach applies to other industries. His idea suggests approaching users as ordinary people in extraordinary environments or as extraordinary people in ordinary environments. By doing so, it is possible to design for people as their circumstances change temporarily (e.g., broken leg), situationally (e.g., multi-tasking activities), genetically (e.g., disability), or naturally (e.g., ageing) over time.

It can be argued that COVID-19 has situated humans in an extraordinary environment since March 2020 and is likely to continue to do so for a long time to come. The businesses that have succeeded most during COVID-19 are those who put employees first, had an agile foundation upon which to build, and made change happen proactively $[77,78]$. One key to doing this work well is meaningful user engagement, whether discussing with employees or clients. Therefore, as the Harvard Business Review article proposed in 2018 before COVID-19 became a reality, it is vitally important to "focus on inclusion - not just diversity" by "understanding who [people] really are" when working to design for people's needs and wants [79]. This is true in business, and continues to be true when designing in the built environment.

\subsection{Designing with and for Extraordinary People}

COVID-19 offers an excellent case study in preparing for the unexpected. Indeed, "In pandemic times, designers are newly aware of uncertainty and the need to prepare for sudden changes of plans" [29]. Designing for this uncertainty can be done by practicing Inclusive Design with and for users.

Some of the most appreciated and sustainable designs are derived from designing with and for intended users, not relying on guidelines alone. This is true throughout academia [80] and industry [29]. In an interview with an access consultant in Canada, she reflected on the underwhelming results of policy-driven projects, stating that "doing evaluations, having feedback from users, [and] looking at unsolicited feedback [made it] very apparent [to her] that...if minimums were being met, they weren't satisfying users, [especially] users of a range of abilities, conditions and personal situations" [54]. Academia [80] and industry [29] agree that lackluster designs and corresponding responses result when policy alone drives design. Engagement with user groups offers the perspectives needed to make a difference and therefore must be included.

By employing creative methods, as suggested by Coleman in his initial Inclusive Design paper, with the intended users, it is likely that more effective design will result. Treviranus encapsulated this thought when she stated "we need to recruit the most relevant and authentic expertise to the design team, namely the edge users or pioneers themselves...not as research participants and subjects of study and analysis, but as fullfledged design team members, or co-designers", [thereby putting substance behind the 'nothing about us without us' terminology known throughout disability literature] [4].

\subsection{Ensuring Extraordinary Design with Extraordinary Designers}

One of the best ways to ensure Inclusive Design is to involve designers-professional architects, engineers, projects planners - who identify as physically, mentally, or socially diverse. If this can be done in addition to engaging users or occupants of the spaces, even 
better. To ensure that these professionally diverse voices can be "heard" and "acted on" to ensure inclusion, it is important that there be diversity and a sense of belonging instilled as a core value in professional communities.

Indeed, "Diversification is critical in architecture because ideas about race, gender, ability, and disability are formed and reproduced in the design and construction of buildings and urban spaces. The absence of disabled architecture students, architects, and particularly academic and institutional leaders within the US relegates people with disabilities to being a topic of discussion versus agents of change." [81] Groups emphasising race (e.g., National Organization of Minority Architects) [82] and gender (e.g., Society of Women Engineers) diversity exist but require further support $[83,84]$.

Unfortunately, there has been little emphasis on understanding and encouraging disability representation (physical, mental, or social) in design professions. In July 2017, the American Society of Civil Engineers' Committee on Diversity and Inclusion (CDI) and Committee on Ethical Practice (CEP) proposed Canon 8 of the Society's Code of Ethics "to address concerns about, and the realities of, inequities and inequalities in the civil engineering profession" [85]. However, the architecture profession is even further behind. "In the United States, people with disabilities in the architecture profession and architectural academia are statistically invisible. Neither the American Institute of Architects, the National Council of Architectural Registration Boards, nor the Association of Collegiate Schools of Architecture collect data on the number of architects or architecture students in the United States who self-identify with physical or cognitive disabilities" [81].

To truly ensure diversity, it is important to bring awareness to these issues and enact transformational change relating to educational spaces, design pedagogy, and professional development support. This is the next step in ensuring Inclusive Design can became a pervasive element in all design.

\section{Conclusion}

In this paper, the authors explored Inclusive Design across three continents: North America, Europe and the UK, and Australia. Through this exploration, the authors identify lessons learned, best practices, and key takeaways relating to how and why Inclusive Design is theoretically good as a design practice but also excellent for business.

While there is variation across terms within the Inclusive Design "continuum" it is important to maintain an agile approach to related terminology. While flexibility is important to deter exclusive design language, this research team prefers terms that are human-centred [28] and recognises the uniqueness and celebrates the diversity and abilities of each individual. Some terms that meet this criteria include Newell's Designing for the Extraordinary, Herssens' Designing for More [86] and Winance's Designing for Uniqueness (i.e., Unique User Design) [16].

No matter the terminology, Inclusive Design cannot be fully realised through research, best practice implementation, and policy enactment alone. It is critical that diverse users be included in the design process to ensure fairness in design [15] and exercise their right 
to participate [80]. Indeed, as Stefan Johansson suggests, "design for participation and inclusion will follow" [87]. It seems a logical approach then for Inclusive Design research and practice to be inclusive of co-design, as a means towards designing with and not just for user groups.

By building on Inclusive Design's research definition and industry practice to date and layering in Co-design as a pluralistic approach that values designing for the 'extraordinary', 'more', or 'uniqueness', the authors believe that it is indeed possible to design for Inclusion, as both a market differentiator and a diversity-driven participatory initiative.

\section{References}

[1] DOGA, editor. Innovating with People-Inclusive Design and Arch. Design and Architecture Norway (DOGA); 2018.

[2] Krznaric R. Empathy: a handbook for revolution. London: Rider Books; 2014.

[3] Treviranus J. The Three Dimensions of Inclusive Design: Part One **. Medium 2018. https://medium.com/fwd50/the-three-dimensions-of-inclusive-design-partone-103cad1ffdc2 (accessed August 14, 2019).

[4] Treviranus J. The Three Dimensions of Inclusive Design, Part Two**. Medium 2018. https://medium.com/@jutta.trevira/the-three-dimensions-of-inclusivedesign-part-two-7cacd12b79f1 (accessed August 14, 2019).

[5] Treviranus J. The Three Dimensions of Inclusive Design, Part Three**. Medium 2018. https://medium.com/@jutta.trevira/the-three-dimensions-of-inclusivedesign-part-three-b6585c737f40 (accessed August 14, 2019).

[6] Pullin G. Design Meets Disability. Cambridge, Mass: MIT Press; 2009.

[7] CABE. The principles of inclusive design: they include you. Commission for Architecture and the Built Environment 2006:20.

[8] Dillon I, Green J. Universal Design | asla.org. Professional Practice-Universal Design 2019. https://www.asla.org/universaldesign.aspx (accessed January 7, 2021).

[9] World Health Organization (WHO). Disability and health 2020. https://www.who.int/news-room/fact-sheets/detail/disability-and-health (accessed March 3, 2021).

[10] Pasqualotti A, Amaro F, Neves BB. Exergames and Neuropsychological Functions in Older Adults: An Experimental Approach. In: Neves BB, Vetere F, editors. Ageing and Digital Technology: Designing and Evaluating Emerging Technologies for Older Adults, Singapore: Springer Singapore; 2019, p. 247-65. https://doi.org/10.1007/978-981-13-3693-5_15.

[11] McCown J. Supporting Neurodiversity in the Workplace and Beyond. Metropolis 2021. https:/www.metropolismag.com/homepage/neurodiversity-hok/ (accessed February 19, 2021).

[12] Prüss-Üstün A, Corvalán C. Preventing Disease through Healthy Environments. France: 2006.

[13] Rieger J, Iantkow M. The forgotten sustainability: A socially conscious paradigmatic shift in design. In: Prochner I, Antoniuk T, editors. Situating Design in Alberta, University of Alberta Press; 2021. 
[14] Imrie R, Luck R. Designing inclusive environments: rehabilitating the body and the relevance of universal design. Disability and Rehabilitation 2014;36:1315-9. https://doi.org/10.3109/09638288.2014.936191.

[15] Bianchin M, Heylighen A. Fair by design. Addressing the paradox of inclusive design approaches. The Design Journal 2017;20:S3162-70. https://doi.org/10.1080/14606925.2017.1352822.

[16] Winance M. Universal design and the challenge of diversity: reflections on the principles of UD, based on empirical research of people's mobility. Disability and Rehabilitation 2014;36:1334-43. https://doi.org/10.3109/09638288.2014.936564.

[17] Maisel JL, Steinfeld E, Basnak M, Smith K, Tauke MB. Inclusive Design: Implementation and Evaluation. Milton, UNITED KINGDOM: Taylor \& Francis Group; 2017.

[18] Rieger J. Rieger, Janice. "Universal Design: A Shifting Paradigm", IDEC Exchange, Indianapolis: IDEC Publications, Summer 2012: 24. IDEC Exchange 2012.

[19] Rieger J, Iantkow M. The Forgotten Sustainability: A Socially Conscious Paradigmatic Shift in Design n.d.:32.

[20] Dixon-Fyle S, Dolan K, Hunt V, Prince S. Diversity wins: How inclusion matters | McKinsey 2020. https://www.mckinsey.com/featured-insights/diversity-andinclusion/diversity-wins-how-inclusion-matters (accessed February 19, 2021).

[21] Dixon-Fyle S, Dolan K, Hunt V, Prince S. Diversity wins: How inclusion matters | McKinsey Report. 2020.

[22] Norwegian Ministry of Children, Equality and Social Inclusion. The Government's Action Plan for Universal Design | 2015-2019. 2016.

[23] Rajagopal A. Why Interior Designers Must Fight Climate Change. Metropolis 2020. https://www.metropolismag.com/interiors/interior-designers-climatecarbon/ (accessed February 19, 2021).

[24] Chan DM, Zoellick MRB. World Report on Disability 2011:24.

[25] WHO. WHO | What is Healthy Ageing? WHO 2015. http://www.who.int/ageing/healthy-ageing/en/ (accessed January 18, 2020).

[26] WHO. Ageing and health 2018. https://www.who.int/news-room/factsheets/detail/ageing-and-health (accessed January 16, 2020).

[27] Americans with Disabilities Act (ADA). Accommodating Persons with Environmental Sensitivities: Challenges and Solutions | ADA National Network 2014. https://adata.org/event/accommodating-persons-environmentalsensitivities-challenges-and-solutions (accessed February 19, 2021).

[28] Goldhagen SW. Journal 5 - human centered design. Journal of Urban Design and Mental Health 2018;5.

[29] Williamson B. Why Are There So Few Great Accessible Buildings? Metropolis 2020.

[30] US Department of Justice. 2010 ADA Standards for Accessible Design 2010. https://www.ada.gov/2010ADAstandards_index.htm (accessed February 19, 2021).

[31] Winer R. Why universal design is critical to creating truly healthy spaces. WELL International WELL Building Institute | Articles 2019. https://resources.wellcertified.com/articles/why-universal-design-is-critical-tocreating-truly-healthy-spaces/ (accessed November 30, 2019). 
[32] What is Universal Design | Centre for Excellence in Universal Design. What Is Universal Design 2020. http://universaldesign.ie/What-is-Universal-Design/ (accessed December 17, 2020).

[33] Universal Design | asla.org n.d. https://www.asla.org/universaldesign.aspx (accessed November 30, 2019).

[34] Verma I. Housing Design for All? The challenges of ageing in urban planning and housing design - The case of Helsinki. Aalto University publication series DOCTORAL DISSERTATIONS, 123/2019, 2019.

[35] Design for All Europe. EIDD - DfA Europe n.d. http://dfaeurope.eu/ (accessed November 30, 2019).

[36] Mosca EI, Herssens J, Rebecchi A, Capolongo S. Inspiring architects in the application of design for all: knowledge transfer methods and tools. 1 2019;9:124. https://doi.org/10.17411/jacces.v9i1.147.

[37] Mikus J, Høisæther V, Martens C, Spina U, Rieger J. Employing the Inclusive Design Process to Design for All. In: Di Bucchianico G, Shin CS, Shim S, Fukuda $\mathrm{S}$, Montagna $\mathrm{G}$, Carvalho C, editors. Advances in Industrial Design, Cham: Springer International Publishing; 2020, p. 69-76. https://doi.org/10.1007/978-3030-51194-4_10.

[38] Nordby K. Design for All: Shaping the end-users_Tel-eEurope: ETSI's involvement in laying the foundation for an all-inclusive eEurope., Nice, France: 2003.

[39] UN Department of Economic and Social Affairs. Timeline of Events | Disability 2015. https://www.un.org/development/desa/disabilities/convention-on-therights-of-persons-with-disabilities/timeline-of-events.html (accessed February 19, 2021).

[40] University of Washington (UW). What is the difference between accessible, usable, and universal design? | DO-IT 2019. https://www.washington.edu/doit/what-difference-between-accessible-usableand-universal-design (accessed February 19, 2021).

[41] Duncan R. Design Pioneer and Visionary of Universal Design, Remembering Ron Mace | LinkedIn 2018. https://www.linkedin.com/pulse/design-pioneer-visionaryuniversal-remembering-ron-mace-duncan/ (accessed January 11, 2021).

[42] University of Buffalo (UB). The Goals and Benefits of Universal Design 2021. http://www.buffalo.edu/access/help-and-support/topic3.html (accessed February 19, 2021).

[43] IWARSSON S, STÅHL A. Accessibility, usability and universal designpositioning and definition of concepts describing person-environment relationships. Disability and 2009. https://doi.org/10.1080/dre.25.2.57.66.

[44] EIDD. Design for All Europe. EIDD - DfA Europe 2021. https://dfaeurope.eu/ (accessed February 20, 2021).

[45] EIDD. The EIDD Stockholm Declaration 2004 - EIDD - DfA Europe - Are.na 2004.

[46] Rieger J, Chamorro-Koc M, Herssens J, Strickfaden M, Bosserez A. Design for all (DFA) week: Vis-ability 2019. https://research.qut.edu.au/designlab/wpcontent/uploads/sites/2/2019/10/DfAW-eBook.pdf (accessed March 3, 2021).

[47] Coleman R. The Case for Inclusive Design, Toronto, Canada: DesignAge, Royal College of Art, London, UK; 1994. 
[48] John Clarkson P, Coleman R. History of Inclusive Design in the UK. Applied Ergonomics 2015;46:235-47. https://doi.org/10.1016/j.apergo.2013.03.002.

[49] CABE. Inclusion by Design: Equality, Diversity, and the Built Environment. London, UK: 2008.

[50] Wayback Machine. Laurent House - Rockford, IL 2013. https://web.archive.org/web/20130924132137/http://laurenthouse.com/about.htm 1 (accessed February 20, 2021).

[51] Gallaudet University. DeafSpace. Campus Design and Planning-DeafSpace 2021. https://www.gallaudet.edu/campus-design-and-planning/deafspace/ (accessed February 20, 2021).

[52] CCD. The Canadian Museum For Human Rights: A Beacon of Access and Inclusion | Council of Canadians with Disabilities 2014. http://www.ccdonline.ca/en/socialpolicy/access-inclusion/CMHR18Sept2014 (accessed February 20, 2021).

[53] Rieger J, Strickfaden M, Rolfe A. Case study report: Canadian Museum for Human Rights, Winnipeg, Canada. 2018.

[54] Rieger JL. Doing Dis/ordered Mapping/s: Embodying Disability in the Museum Environment. ERA 2016. https://doi.org/10.7939/R3WS8HT96.

[55] CMHR. The Building | Canadian Museum for Human Rights 2021. https://humanrights.ca/about/the-building (accessed February 20, 2021).

[56] Horowitz J. Ikea and the Queen of Sweden are designing homes for people with dementia. CNN 2019. https://www.cnn.com/2019/08/08/business/ikea-swedendementia/index.html (accessed February 20, 2021).

[57] Crook L. IKEA and Queen of Sweden adapt modular BoKlok housing for the elderly. Dezeen 2019.

[58] Conklin E. IKEA and the Queen of Sweden update the retirement home for dementia. The Architect's Newspaper 2019.

[59] Associated Press. New Elevator, Pathways to Open Acropolis to Disabled Visitors. AFAR 2020. https://www.afar.com/magazine/acropolis-will-soon-become-fullyaccessible-to-disabled-

visitors?utm_source=Sailthru\&utm_medium $=$ email\&utm_campaign $=120620 \% 2$ 0CaliLockdown\&utm_content=Final\&utm_term=Daily $\% \overline{2}$-WWander $\% 20 \% 28 \mathrm{Hav}$ e\%20opened\%20newsletter\%20before\%29 (accessed January 11, 2021).

[60] McGivern H. How to make museums more accessible for disabled people? Ask them. The Art Newspaper 2019.

[61] Wellcome Collection. Accessibility. Wellcome Collection 2021. https://wellcomecollection.org/pages/Wvm2uiAAAIYQ4FHP (accessed February 20, 2021).

[62] Wellcome Collection. Being Human. Wellcome Collection 2021. https://wellcomecollection.org/exhibitions/XNFfsxAAANwqbNWD (accessed February 20, 2021).

[63] Marshall A. Is This the World's Most Accessible Museum? The New York Times 2019.

[64] Rieger J, Strickfaden M. Wandering on the Braille Trail. Wandering on the Braille Trail 2018. https:/eprints.qut.edu.au/134109/ (accessed March 3, 2021).

[65] Rieger J. Reframing Universal Design: Creating Short Videos for Inclusion. 4th Australian Universal Design Conference, Melbourne, Australia: 2020. 
[66] Stephens K. Brisbane Braille Trail extended through CBD. Brisbane Times 2013. https://www.brisbanetimes.com.au/national/queensland/brisbane-braille-trailextended-through-cbd-20131017-2vpe4.html (accessed March 3, 2021).

[67] Mirvac. Architecture and Design 2020. https://200george.mirvac.com/workplace/building-overview/architecture-anddesign (accessed February 21, 2021).

[68] ASLA. ASLA Mission, Vision, Values and Culture | asla.org 2021. https://www.asla.org/ContentDetail.aspx?id=58578 (accessed February 20, 2021).

[69] Budds D. Why inclusive cities start with safe streets. Curbed 2019. https://archive.curbed.com/2019/8/28/20835301/universal-streets-accessiblestreet-design (accessed February 20, 2021).

[70] IWBI. Organizational Structure | WELL Standard 2021. https://standard.wellcertified.com/organizational-structure (accessed February 20, 2021).

[71] IWBI. The WELL Building Standard: v1 with Q1 2019 addenda. International $\begin{array}{llll}\text { WELL Building } & \text { Institute }\end{array}$ https://www.wellcertified.com/en/standard (accessed April 20, 2019).

[72] International Well Building Institute (IWBI). WELL v2 Standard 2021. https://v2.wellcertified.com/wellv2/en/overview (accessed February 20, 2021).

[73] Rajagopal A. Redefining Fitness: How WELL v2 Is Driving More Inclusive Interiors - Metropolis. Metropolis 2019.

[74] WELL. Task Force Member Directory on COVID-19 \& Other Respiratory Infections | IWBI 2021. https://www.wellcertified.com/powerofplace/task-forcedirectory (accessed February 21, 2021).

[75] HubSpot 2021 Diversity, Inclusion, \& Belonging Report n.d. https://www.hubspot.com/diversity/report (accessed February 19, 2021).

[76] Newell AF, Cairns AY. Designing for Extraordinary Users. Ergonomics in Design 1993;1:10-6. https://doi.org/10.1177/106480469300100405.

[77] Agarwal DP. How Do We Design Workplaces For Inclusivity And Diversity. Forbes 2018. https://www.forbes.com/sites/pragyaagarwaleurope/2018/07/19/how-inclusiveis-your-organisation-here-is-how-to-use-inclusive-design/ (accessed February 12, 2021).

[78] Arora R. Which Companies Did Well During The Coronavirus Pandemic? Forbes 2020. https://www.forbes.com/sites/rohitarora/2020/06/30/which-companies-didwell-during-the-coronavirus-pandemic/ (accessed February 20, 2021).

[79] To Retain Employees, Focus on Inclusion - Not Just Diversity. Harvard Business Review 2018.

[80] Rieger J. Right to Participate: Co-designing Disability Policies in Australia, n.d.

[81] Gissen D. Why are there so few disabled architects and architecture students? The Architect's Newspaper 2018.

[82] Morley JB. National Organization of Minority Architects redefines mission. The Architect's Newspaper 2020.

[83] Smith L, Smith L, Smith L. One Microsoft designer's quest to make the industry more inclusive. Fast Company 2020. https://www.fastcompany.com/90546988/this-microsoft-designer-has-spent-15years-teaching-black-and-brown-kids-to-be-creative-what-hes-learned-couldchange-design (accessed February 20, 2021). 
[84] Hilder R. Design's gender problem, and what you can do about it. Creative Bloq 2020. https://www.creativebloq.com/features/join-the-fight-for-gender-equalityin-design (accessed February 20, 2021).

[85] Pearson YE, Simmons DR. Diversity and Inclusion in Civil and Environmental Engineering. Journal of Professional Issues in Engineering Education and Practice 2018;144:02018001. https://doi.org/10.1061/(ASCE)EI.1943-5541.0000389.

[86] Herssens J. Designing Architecture for More. A Framework of Haptic Design Parameters with the Experience of People Born Blind(Doctoralthesis) Department of Arts and Architecture, PHL University College-University Hasselt: Association Faculty Universiteiten and Hogescholen Limburg, Hasselt 2011.

[87] Johansson S. Design for Participation and Inclusion will Follow : Disabled People and the Digital Society. KTH Royal Institute of Technology, 2019. 